Function and Disability Journal ISSN: 2588-6304

Original Article

\title{
The Effects of Muscular Flexibility and Strength Imbalance on Lower Limb Injuries in Female Martial Arts Athletes
}

\author{
Sara Heidarian ${ }^{1}$, Ali Amiri ${ }^{* 2}$, Aliashraf Jamshidi ${ }^{3}$ \\ 1. MSc Student, Department of Physiotherapy, School of Rehabilitation Science, Iran University of Medical Sciences and \\ Health Services, Tehran, Iran \\ 2. Assisstant Professor, PhD, PT. Department of Physiotherapy, School of Rehabilitation Science, Iran University of \\ Medical Sciences and Health Services, Tehran, Iran \\ 3. Associated Professor, PhD, PT. Department of Physiotherapy, School of Rehabilitation Science, Iran University of \\ Medical Sciences and Health Services, Tehran, Iran
}

\begin{tabular}{l} 
Article Info \\
\hline Received: $2018 / 02 / 30$ \\
Accepted: $2018 / 05 / / 30$ \\
Published Online: $2018 / 10 / 29$ \\
DOI: \\
10.30699/fdisj.01.2.37 \\
How to Cite This Article \\
Heidarian S, Amiri A, \\
Jamshidi A. The Effects of \\
Muscular Flexibility and \\
Strength Imbalance on Low- \\
er Limb Injuries inFemale \\
Martial Arts Athletes. Func- \\
tion and Disability Journal. \\
2018 (spring).Vol: 1.No:2 \\
Pages: $37-46$
\end{tabular}

Use your device to scan and read the article online

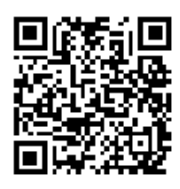

\section{ABSTRACT}

Background and Objective: Owing to the high prevalence of injuries among female martial arts athletes, the effects of flexibility and muscular imbalance on lower limb injuries of female martial arts athletes during a competition season was studied.

Methods: In this cross-sectional study, 66 professional female martial arts athletes of country (aged 15-40), prior to the season, were evaluated for muscle isometric strength and the flexibility assessment, in the ankle joints, knees and hips. During the training and holding of the tournament, the researcher followed up the created injuries and registered them by the physician or physiotherapist of the team. Paired t-test and SPSS 17 software were used to examine the relationship between the strength of the agonist / antagonist and flexibility in case of occurring injury.

Results: The only significant difference between the flexibility in the right hip abductors $(P=0.02)$ and the evertor / invertor strength ratio in the right ankle $(P=0.007)$ was obtained with lower limb injury, and no significant statistical differences were found between the other parameters.

Conclusion: The insufficiency of muscle force in hip joints and muscle strength imbalance in ankle joints can be important internal factors in incidence of injuries in female martial arts athletes.

Keywords: Martial arts, Muscle strength, Flexibility, Lower limb injuries

Copyright (C) 2018, Function and Disability Journal. This is an open-access article distributed under the terms of the Creative Commons Attribution-noncommercial 4.0 International License which permits copy and redistribute the material just in noncommercial usages, provided the original work is properly cited.

\section{Introduction}

Given the popularity of martial arts among women in Iran, the number of participants in these disciplines has been growing rapidly in the past years. These sports are contact type, and due to the diversity of training and strike strategies in these kinds of sports, the occurrence of different injuries in martial arts is unavoidable.

Based on Consumer Product Safety Commission (CPSC) reports, more than 35,000 people suffered moderate to severe injuries in this type of sport, including ligament sprain, muscular strain and less fracture and dislocation of the joints, which varies according to the type of martial arts. For example, damage to lower limb injuries are greater in Wushu and Taekwondo (Bahr and Holme, 2003).

The strength and flexibility of joints are the main internal parameters that are often used to evaluate muscle function.

Researchers in the field of flexibility and imbalance of muscle strength and its association with injuries, believe that, if there is a significant difference in muscle strength and range of motion in the contralateral joints in athletes, they will not only decline in exercise performance, but also most of them in some way will suf- 
fer from physical damage, especially musculoskeletal disorders (Tyler et al., 2001; Gilchrist et al., 2000).

Most studies on the relationship between the lower limb predisposing factors and the injury in martial arts athletes are retrospective based on their previous damage, and there is little follow-up and prospective research in a particular period of time in these fields. Considering, therefore, that research on the role of flexibility and muscle strength imbalance in lower limbs of female martial arts athletes were not found, the research seems to be aimed at assessing these two factors as prospective follow-up is necessary.

\section{Materials and Methods}

In this cross-sectional study, the data were collected through objective measurement of isometric muscle strength and flexibility, as well as the diagnosis of a physician or physiotherapist of the team in the event of injury. Also, due to the fact that the researcher accompanies the subjects during the whole season and collects data at the same time, this research is prospective. At first, all 78 professional female martial arts athletes of country (mean aged 18.8), in four disciplines of Judeo, Karate, Wushu and Taekwondo participated. 12 of them were excluded, so 66 athletes were selected to study and evaluated in muscle strength and flexibility parameters before the start of the tournament, and their damage was pursued. The athletes who suffered injuries before the training began (for getting ready to take part in competition) or less than 2 months of their previous injury, were excluded from the population.

Data is collected in 2017, during a period of 12 weeks of competition sessions. Before the assessment, subjects did regular warm-up. To measure the Maximum Voluntary Isometric Contraction (MVIC) of all muscles, the Emada model manual dynamometer made in the United States, with a capacity of 500 $\mathrm{N}$, (accuracy of one out of tenth of Newton) was used. (MVIC) was kept for 5-3 seconds, and was repeated three times, and the average of these values was calculated and recorded on Newton's basis.

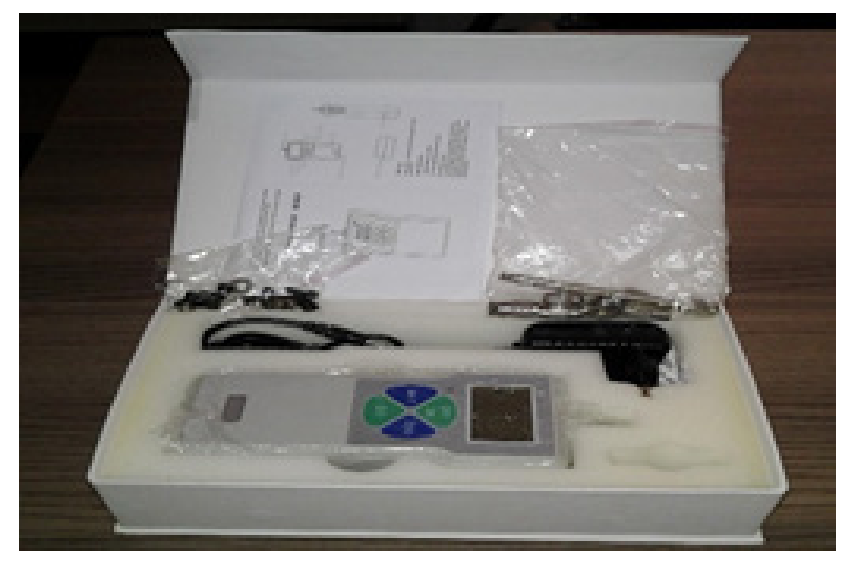

Fig 1. Emada dynamometer

This was conducted for both lower limbs. To avoid fatigue, 30 seconds were restored every time, and there were 3 minutes of rest between the force measurements of each muscle group.

Also, for measuring muscle flexibility, goniometer was used. In both lower extremities, the muscles flexibility of the joints were measured in degrees on three occasions and SPSS 17 software and paired t-test were used to analyze data.

The results of this study are apt for physiotherapists, team physicians and sports societies.

\section{Methods to Measure Muscle Strength}

\section{The Evertor Muscles}

The subject was in supine position, the pelvis, the thighs and legs were firmly placed to prevent additional movements. Ankle was put in a 10-degree planar flexion condition. Then the manual dynamometer on the outside of the leg was placed exactly on the fifth metatarsus and the maximum resistance was applied, and we asked the subject to evert the ankle with maximum force.

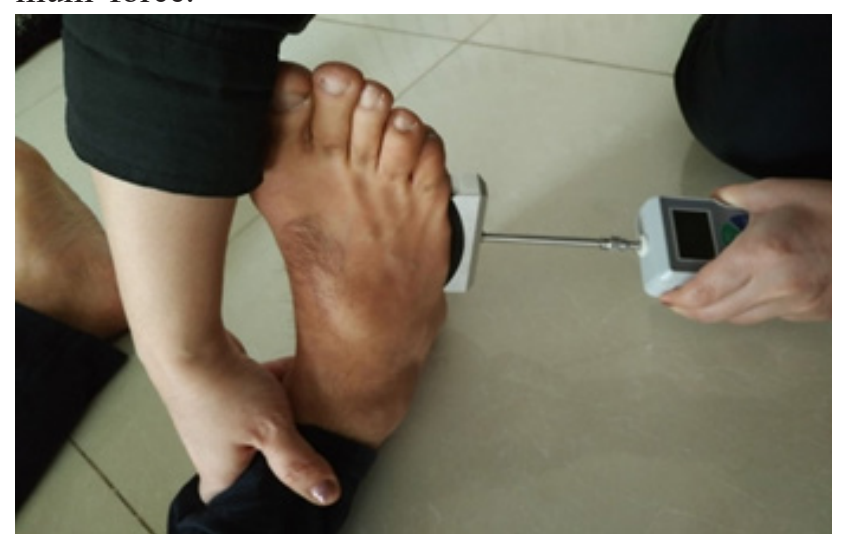

Fig 2. Evertor muscle strength measurement 
39. The Effects of Muscular Flexibility and Strength Imbalance...

\section{The Invertor Muscles}

The position is similar to the above measurement. Then the manual dynamometer was placed on the front of the foot exactly on the first metatarsal and the maximum resistance was applied and the subject was asked to invert the ankle with maximum force (Alfuth and Hahm, 2016).

\section{The Dorsiflexor Muscles}

The subject was lying supine, the pelvis, knees and ankles were set to zero. The ankles were immobilized by the examiner. Manual dynamometer, exactly above the metatarsus phalanges joints, was placed on the back of the forefoot and maximum resistance was applied. We asked the subject to dorsiflex the ankle with maximum force.

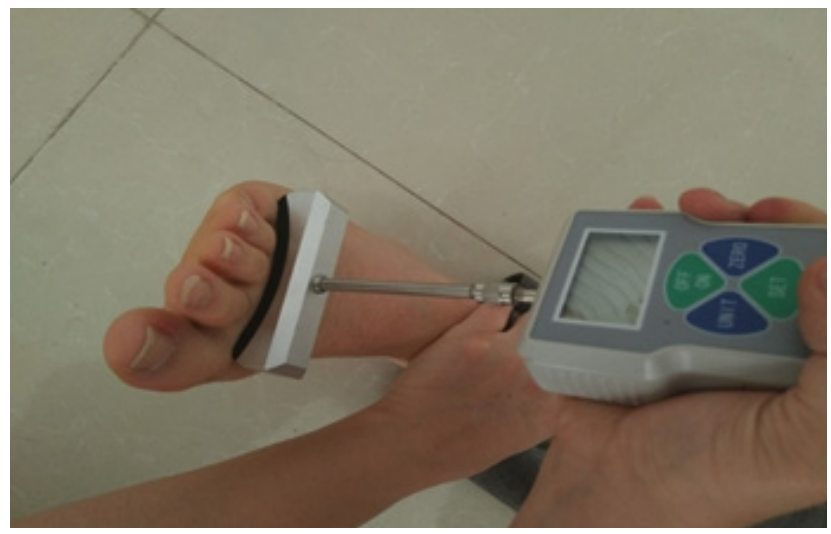

Fig 3. Dorsiflexor muscle strength measurement

\section{The Plantar Flexor Muscles}

The position is similar to the above measurement. The manual dynamometer, exactly above the metatarsus phalanges joints, was positioned at the sole of foot and maximum resistance was applied. We asked the subject to plantar flex the ankle with maximum force (Bohannon, 1986).

\section{The Extensor Muscles}

The subject sat, the thighs and knees were bent up to $90^{\circ}$ and the subject kept the two sides of the chair with her hands. Manual dynamometer was placed in front of the leg precisely above the ankle joint and the maximum resistance was applied. The subject was asked to extend the knee with maximum force.

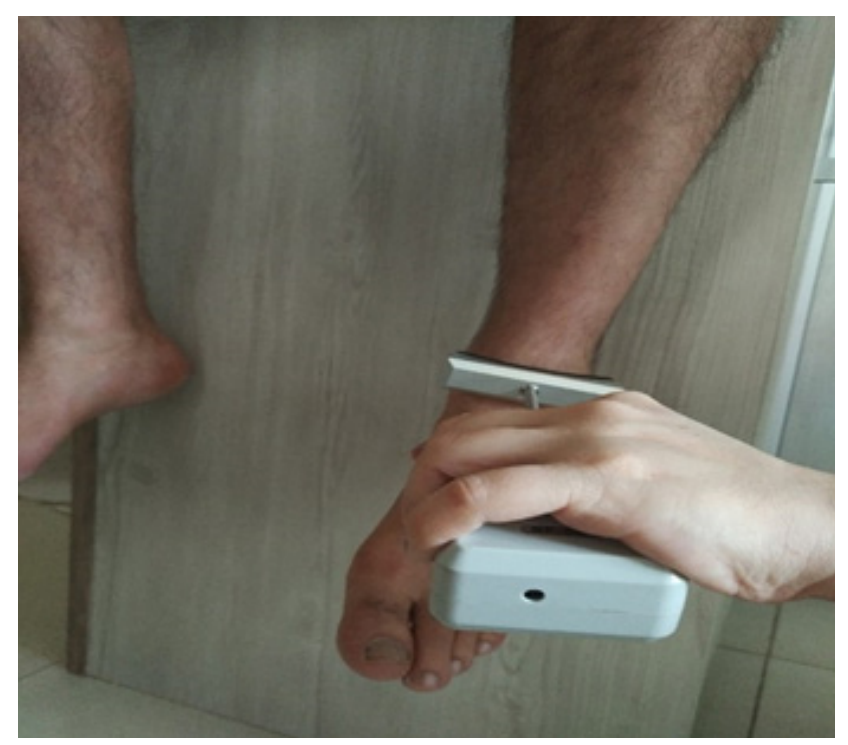

Fig 4. Knee extensor muscle strength measurement

\section{The Flexor Muscles:}

The position is similar to the above measurement. A manual dynamometer was placed at the back of the leg precisely above the ankle joint and the maximum resistance was applied. The subject was asked to bend the knee with the maximum force(Florence et al., 2013).

\section{The Abductor Muscles}

The subject was lying on the side and the lower extremity of the test side was posited upward. The pelvis was immobilized by the examiner. A manual dynamometer was placed on the lateral epicondyle of the thigh and the maximum resistance was applied. The subject was asked to abduct her adducted thigh with a maximum force.

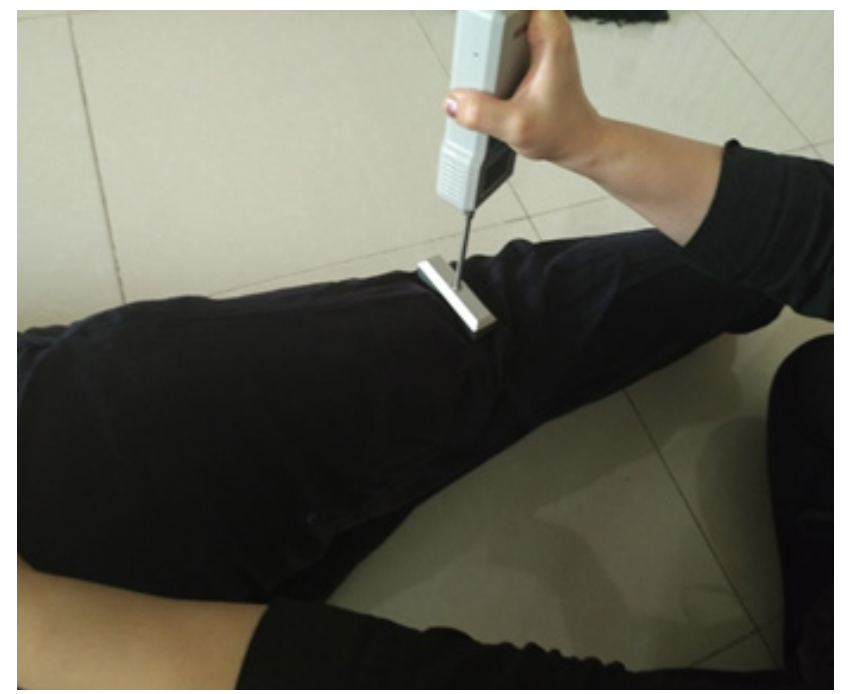

Fig 5. Abductor muscle strength measurement 


\section{The Adductor Muscles:}

The position is similar to the above measurement. A manual dynamometer was placed on the medial epicondyle of the thigh, while the end surface of dynamometer was fixed to the lower limb. Then the maximum resistance was applied. The subject was asked to adduct her thigh from the abduction with maximum force(Thorborg et al., 2010).

\section{Methods for Measuring Flexibility}

\section{Hip Adductors}

The subject was lying supine on the mattress, so that her lower limbs were side by side and in complete adduction (for the spine to be correctly placed on the mattress, a linear measure was used in the middle of the mattress). Two markers were placed on the highest point of the anterior-superior-iliac spine. Another marker was placed on the right patella bone. At the beginning of the movement, to measure the flexibility of right adductor muscles, the end of the fixed arm of the glass goniometer was posited on the lower left marker and the goniometer axis was posited on the right lower limb marker, and the movable arm was placed along the right lower limb patella bone marker. The subject performed a maximum abduction and its angle was recorded. This action was repeated for the left thighs(Nicol, 1989).

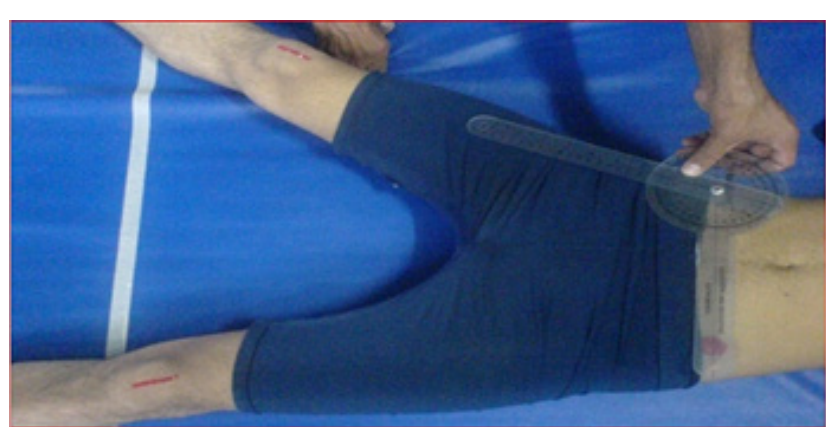

Fig 6. Hip adductors flexibility measurement

\section{Hip Abductors}

The subject was lying prone on the mattress, and two markers were placed on the posterior-superior-iliacspine and a marker on the middle of the back of the thigh bone. The pelvis was fixed, the knee flexed 90 ${ }^{\circ}$ and the hip was completely abducted with the other hand. To measure the flexibility of right abductor mus- cle, the end of the fixed arm of the glass goniometer was putted on the left posterior-superior-iliac-spine and the goniometer axis was on the right posterior-superior-iliac-spine and the movable arm was along the midline of the right thigh. The subject was asked to do maximum adduction while maintaining the knee condition. The difference between the two numbers was calculated, and the angle was recorded and repeated for the other limb.

\section{Knee Flexor}

The subject was lying supine on the mattress that was not soft, the lower limbs extended, so the lumbar and sacrum were straight on the ground. If the lumbar area was not on the floor due to shortening of femoral flexor muscles, a pillow or towel was placed under the knees. Then the subject forced one of the thighs downward to prevent the anterior pelvic tilt. Markers were put on the greater trochanter, lateral epicondyle of thigh and lateral malleolus. The fixed arm of the goniometer was on the greater trochanter, the goniometer axis was on the lateral epicondyle of thigh, and the goniometer's moving arm was placed along the lateral malleolus. The hip was flexed 90 degrees and the subject was asked to lift the desired limb with knee extension while the ankle was free, until a slight limitation or feelings of discomfort was felt. The angle was recorded. Measurements were repeated for other limb as well

\section{Knee Extensors}

The subject was lying prone on mattress, and the examiner was placed in the test side. Markers were put on the greater trochanter, lateral epicondyle of thigh and lateral malleolus. The fixed arm of the goniometer was placed on the greater trochanter, the goniometer axis was on the lateral epicondyle and moving arm of goniometer was along the lateral malleolus. The examiner held the pelvis constantly and the subject was asked to flex the desired knee until the pelvis in side of the test was raised from the mattress or the person felt pain. This was repeated for the other limb.

\section{Ankle Plantar Flexors}

The person sat on the chair and kept the two sides of the chair with her hands. The three markers were mounted on the lower limb. The first marker was 
placed on the proximal end of the fibula, the second marker, on the lateral malleolus and the third marker, along the lateral fifth metatarsal bone. The fixed arm of goniometer was placed on the end of proximal fibula, the goniometer axis on the lateral malleolus and moving arm along the fifth metatarsal bone. The examiner was asked to maximum ankle dorsiflexion, once with extended knee and once with flexed knee. The angle was measured by the goniometer, and the resulting number of differences was recorded and repeated for the other limb.

\section{Ankle Dorsiflexors}

The individual sat on the mattress. A pillow was placed in the proximal part of the thigh so the knee bent from 20 to 30 degrees and the heels were placed upper from the mattress. Three markers were mounted on lower limb. The first marker was placed on the head of the fibula, the second marker, on lateral malleolus and the third one, along the lateral side of fifth metatarsal bone. The fixed arm of goniometer was put on the proximal end of the fibula; the goniometer axis was on lateral malleolus and moving arm along the fifth metatarsal bone. The examiner was asked to maximum ankle plantar flexion. The angle was measured by the goniometer, and the resulting number of differences was recorded and repeated for the other limb.

\section{Subtalar Invertors}

The person sat on the chair, so the lower limb was not placed on the ground. The moving arm of goniometer was placed on the forefoot plantar side and on the head of the metatarsal. The goniometer axis was placed on forefoot medial side and the fixed arm perpendicular to the moving arm. In this case, the starting position was zero. The subject was asked to evert completely and repeat for the other limb.

\section{Subtalar Evertors}

The position is similar to the above measurement. The goniometer axis was placed on forefoot lateral side and the fixed arm perpendicular to the movable arm. In this case, the starting position was zero. The subject was asked to invert completely and repeat for the other limb (Luis, 2001).

\section{Data Collection}

All subjects were monitored during the training period and all injuries were recorded by the physician or team physiotherapist in the injury sheet. To test the research hypotheses and determine their meaningful relationship, inferential statistics with meaningfulness $(P<0.05)$ was used. All statistical calculations were then performed using SPSS17 software and paired ttest was used.

\section{Results}

Based on demographic results, the mean age of subjects was 18.8 years, mean weight was $54.9 \mathrm{~kg}$ and average height was $164.8 \mathrm{~cm}$.

Table (1) shows that out of 40 injured subjects, $42.4 \%$ were grade I, $16.7 \%$ of grade II and only $1.5 \%$ of grade III injuries were reported and all data had normal distributions.

Table 1. Frequency and Percentage of Subjects Suffering Injuries

According to the findings of table (2), all injuries in hip joints were muscular and in ankle joints were ligamentous.

Table 1. Frequency and Percentage of Subjects Suffering Injuries

\begin{tabular}{ccc} 
& Total (Subjects) & Percentage (\%) \\
\hline GRADE I & 28 & 42.4 \\
\hline GRADE II & 11 & 16.7 \\
\hline GRADE III & 1 & 1.5 \\
\hline Subjects not Injured & 26 & 39.4 \\
\hline Total & 66 & 100.0 \\
\hline
\end{tabular}


Table 2. Frequency and Percentage of Kind of Joint Injuries

\begin{tabular}{|c|c|c|c|c|c|}
\hline & & Right & Left & Percent & Total \\
\hline \multirow[t]{2}{*}{ Hip } & Active Components Injuries & 6 & 4 & $100 \%$ & 10 \\
\hline & Passive Components Injuries & - & - & - & \\
\hline \multirow[t]{2}{*}{ Knee } & Active Components Injuries & 5 & 4 & $42.85 \%$ & 21 \\
\hline & Passive Components Injuries & 5 & 7 & $57.14 \%$ & \\
\hline \multirow[t]{2}{*}{ Ankle } & Active Components Injuries & - & - & - & 12 \\
\hline & Passive Components Injuries & 7 & 5 & $100 \%$ & \\
\hline
\end{tabular}

The findings of Table 3 show that there is only a significant difference $(=0.02)$ in relation to the flexibility of the abductor muscles of right hip and the occurrence of injury and the findings of table 4, show that among the injured and healthy people, in terms of muscle strength of the right lower extremity (agonist
/ antagonist), the only significant difference is in the ratio of evertor / invertor strength, with the level of significance $(P=0.007)$.

And there is no significant difference between healthy and injured subjects in terms of flexibility and muscle strength ratio in left lower limb muscles.

Table 3. Comparison of Right Lower Limb Flexibility in two Healthy and Injured Groups

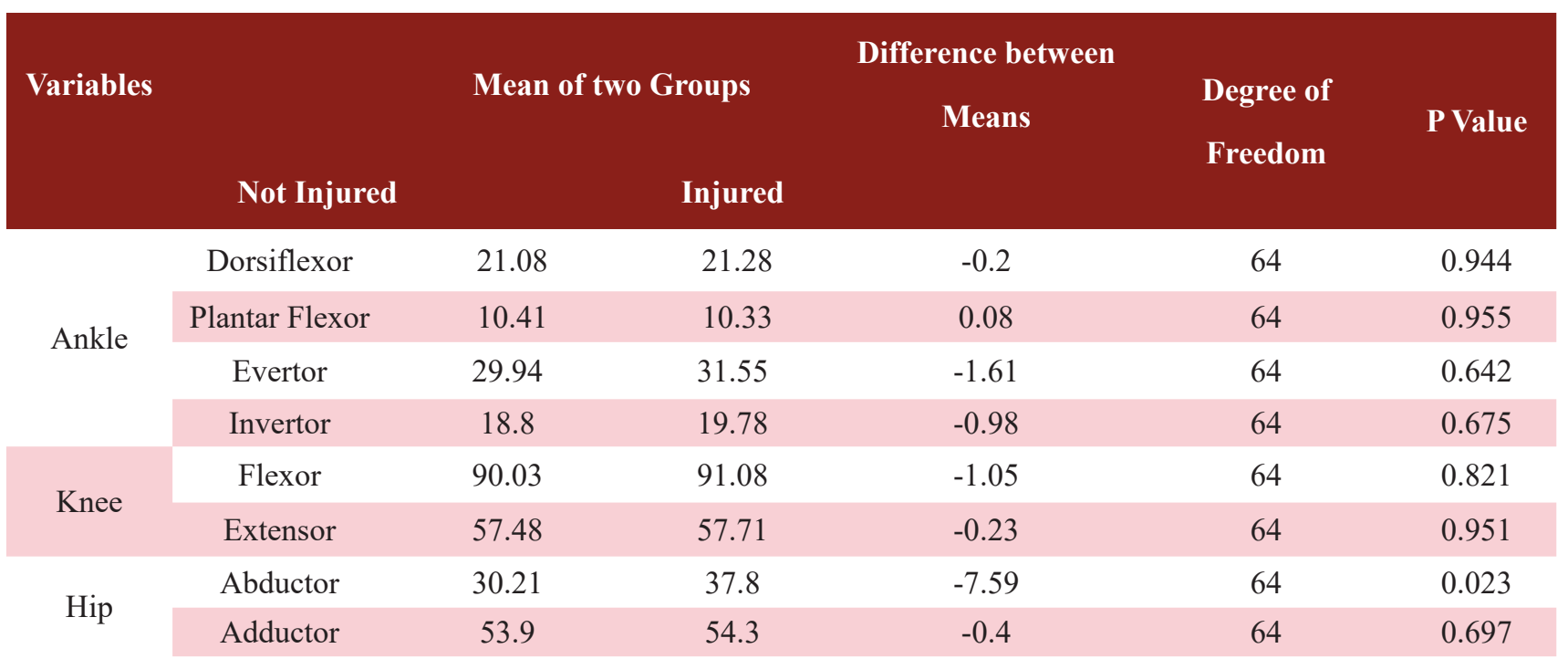

Table 4. Proportion Comparison of Muscle Strength in Right Lower Extremity in both Healthy and Injured Groups

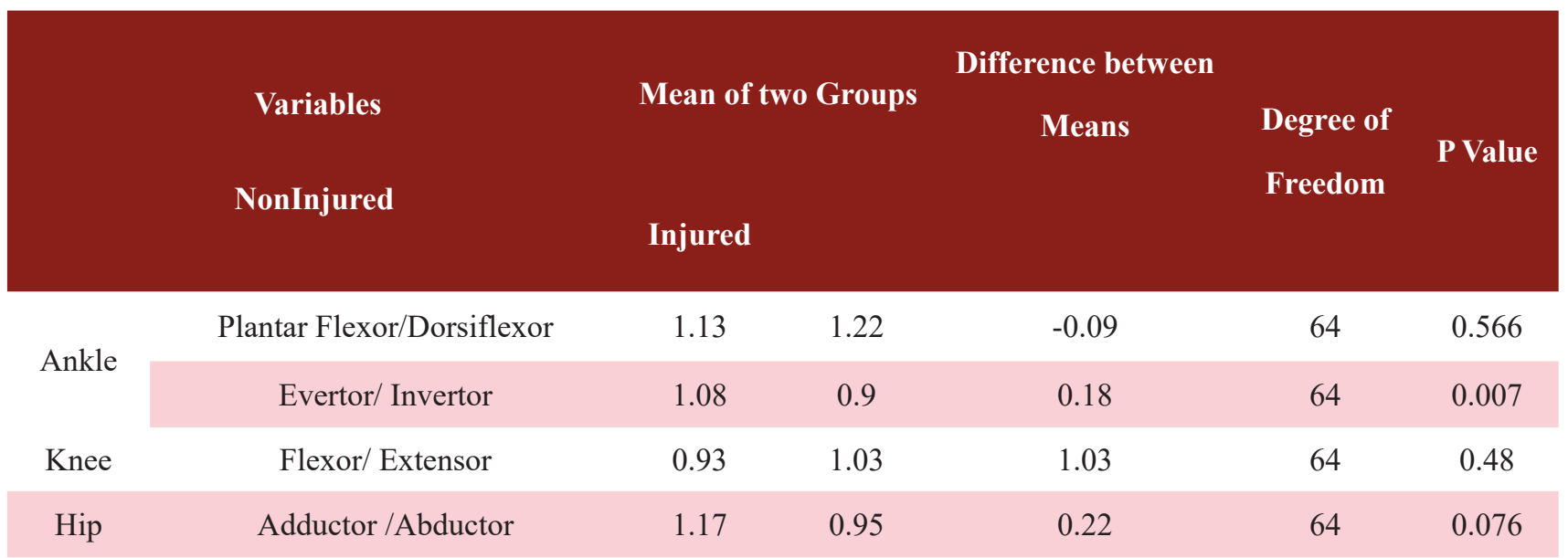




\section{Discussion}

The results of this study showed that there is only a significant difference between the flexibility of the right hip abductors and the right eversion/inversion muscle strength imbalance in the lower limb of the female martial arts athletes with incidence of injuries. In this study, two parameters of muscle strength and flexibility have been investigated as internal factors of injuries.

Flexibility is the main element in the normal biomechanical performance in sports. By changing the force during ROM, in the form of increasing the speed, frequency and time of stress on the joint, the muscle strength are involved to maintain the status in the elastic region. By reaching the range of motion to the boundary limit, these muscles act as anticipation to create a joint stability(Phillips et al., 2007).

In this study, there is a significant difference between increased flexibility of right hip abductors and muscle strain $(P=0.02)$, and all injuries were muscular in hip joints (adductor strain).

Dvorak and Ekstrand have shown, for adductor strain, one of identified risk factors was adductor inflexibility (Ekstrand and Gillquist, 198; Dvorak et al., 2000).

The primary function of this muscle group (adductors), is adduction of thigh in open chain and stabilization of lower extremities and pelvis in close chain, when abductors try to decelerate adducting leg by using an eccentric contraction(Tyler et al., 2010).

The cause of this result, may relate to two approaches: Firstly, as martial arts are multidirectional activities and due to enhancement in adductor range of motion, athletics require a strong concentric contraction of adductors or eccentric contraction of abductors to beer the transmission of large force through ROM. The lack of this mechanism may make it more prone to strain.

And secondly, according to Fricken et al, it is also possible that repetitive movements and excessive use can result in micro trauma and lead to structural changes in the joint. In this case, it seems that body increases flexibility in that joint for compensation(Fricker,
Taunton, and Ammann, 1991).

Another aspect of internal factors investigated in this study is muscle strength ratio.

Regarding the muscle strength imbalance in the occurrence of sports injuries, it can be said that in order to maintain joint stability during movement in a certain ROM, it is necessary that the muscles have sufficient strength to return the elements to the elastic range of motion. Given that for normal movement, coactivation of muscles (agonists and antagonists) is necessary. The balance between their strength is necessary to maintain joint neutral zone stability. So that reducing the correct contraction pattern between these two groups leads to an increased chance of ligament injury(Baratta et al., 1988).

According to this, Thorborg and Tyler (Kristian Thorborg et al., 2011), found that, muscle imbalance strength in pre-match period, had significant role in injury.

Wilkerson et al., (Wilkerson, Pinerola, and Caturano , 1997), in a research on causes of ankle sprain found that there was a significant difference between the ratio of evertor/ invertor muscle strength and ankle sprain, which was also found in this study $(P=0.007)$. Therefore, it can be said that in incidence of ankle sprain, the lack of control of the forces involved on the joint, plays a role. Furthermore, it is possible to say, changing ROM of hips may be the cause of injuries in ankles. According to Mackinnon et al., there was association between decreased hip abduction and stability and ankle injury (MacKinnon and Winter, 1993).

Considering that the injuries (of the ankle sprain and adductor muscle strain) in the right leg, is in the frontal plane, it seems that, the compensation of the forces involved in the joint is low and in case of repetition of movement, there is also a possibility of fatigue and as in martial arts, athletes continuously replace the legs in standing and knocking, the opinions of Dr. Salavati and colleagues can be cited. They stated that in frontal plane, the lower limb controls the effect of standing on one leg and frontal plane muscle tiredness decreases the postural stability in the same plane(Salavati et al., 2007).So any changes in this stability can be an- 
other cause of ankle injuries.

Therefore we can mention that, although only two parameters of internal factors causing injuries have been investigated in this study, in hip joints lack of apt contraction and in ankle joints, low frontal plane instability and muscle strength imbalance may have the essential role in incidence of injuries in female martial arts athletes.

\section{Acknowledgements}

The present paper is extracted from the M.Sc. thesis of the first author, Sara Heidarian : Department

\section{References}

Alfuth, M., \& Hahm, M. M. (2016). Reliability, comparability, and validity of foot inversion and eversion strength measurements using a hand-held dynamometer. International journal of sports physical therapy, 11(1), 72.

Bahr, R., \& Holme, I. (2003). Risk factors for sports injuries - a methodological approach. British journal of sports medicine, 37(5), 384-392.

Baratta, R., Solomonow, M., Zhou, B. H., Letson, D., Chuinard, R., \& D'ambrosia, R. (1988). Muscular coactivation: the role of the antagonist musculature in maintaining knee stability. The American journal of sports medicine, 16(2), 113-122.

Bohannon, R. W. (1986). Test-retest reliability of handheld dynamometry during a single session of strength assessment. Physical therapy, 66(2), 206-209.

Dvorak, J., Junge, A., Chomiak, J., Graf-Baumann, T., Peterson, L., Rosch, D., \& Hodgson, R. (2000). Risk factor analysis for injuries in football players. The American Journal of Sports Medicine, 28(5_suppl), 69-74.

Ekstrand, J., \& Gillquist, J. (1983). Soccer injuries and their mechanisms: a prospective study. Medicine and science in sports and exercise, 15(3), 267-270.

Fricker, P. A., Taunton, J. E., \& Ammann, W. (1991). Osteitis pubis in athletes. Sports medicine, 12(4), 266279.

Kendall, F. P., McCreary, E. K., Provance, P. G., Rodgers, M. M., \& Romani, W. A. (2005). Muscles: Testing and Function, with Posture and Pain (Kendall, Muscles). of Physiotherapy, School of Rehabilitation Sciences, Iran university of Medical Sciences, Tehran. We appreciate the cooperation of all study participants and other people who helped us with conducting this study. This study supported with IUMS Funding

\section{Conflict of interest statement}

The authors declared no conflict of interests.
Philadelphia: Lippincott Williams \& Wilkins.

Luis, A. (2001). Joint Range of Motion and Muscle Length Testing, 2nd Edition. Language Awareness 10 (1), 57-71.

MacKinnon, C. D., \& Winter, D. A. (1993). Control of whole body balance in the frontal plane during human walking. Journal of biomechanics, 26(6), 633-644.

Nicol, A. C. (1989). Measurement of joint motion. Clinical Rehabilitation, 3(1), 1-9.

Phillips, A. T. M., Pankaj, P., Howie, C. R., Usmani, A. S., \& Simpson, A. H. R. W. (2007). Finite element modelling of the pelvis: inclusion of muscular and ligamentous boundary conditions. Medical engineering \& physics, 29(7), 739-748.

Salavati, M., Moghadam, M., Ebrahimi, I., \& Arab, A. M. (2007). Changes in postural stability with fatigue of lower extremity frontal and sagittal plane movers. Gait \& posture, 26(2), 214-218.

Thacker, S. B., Branche, C., Gilchrist, J., Jones, B. H., Sleet, D. A., \& Kimsey, C. D. (2000). Exercise-related injuries among women: strategies for prevention from civilian and military studies. Morbidity and Mortality Weekly Report: Recommendations and Reports, 13-33.

Thorborg, K., Petersen, J., Magnusson, S. P., \& Hölmich, P. (2010). Clinical assessment of hip strength using a hand-held dynamometer is reliable. Scandinavian journal of medicine \& science in sports, 20(3), 493-501.

Thorborg, K., Serner, A., Petersen, J., Madsen, T. M., Magnusson, P., \& Hölmich, P. (2011). Hip adduction and abduction strength profiles in elite soccer players: im- 
45. The Effects of Muscular Flexibility and Strength Imbalance...

plications for clinical evaluation of hip adductor muscle recovery after injury. The American journal of sports medicine, 39(1), 121-126.

Tyler, T. F., Nicholas, S. J., Campbell, R. J., \& McHugh, M. P. (2001). The association of hip strength and flexibility with the incidence of adductor muscle strains in professional ice hockey players. The American journal of sports medicine, 29(2), 124-128.
Tyler, T. F., Silvers, H. J., Gerhardt, M. B., \& Nicholas, S. J. (2010). Groin injuries in sports medicine. Sports health, 2(3), 231-236.

Wilkerson, G. B., Pinerola, J. J., \& Caturano, R. W. (1997). Invertor vs. evertor peak torque and power deficiencies associated with lateral ankle ligament injury. Journal of Orthopaedic \& Sports Physical Therapy, 26(2), 78-86. . 
Function and Disability Journal ISSN: 2588-6304

مقالة يزوهشى

تأثير انعطاف يذيرى و نبود تعادل قدرت عضلات اندام تحتانى روى صدمات اين اندام در زنان رزمى كار

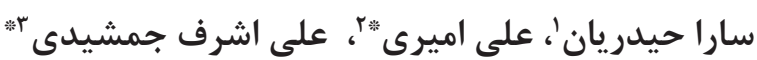

دانشجوى كارشناسى ارشد، كروه فيزيوترايى، دانشكده علوم توانبخشى، دانشاه علوم يزشكى و خدمات بهداشتى درمانى ايران، تمبران، ايران

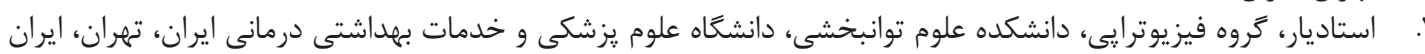

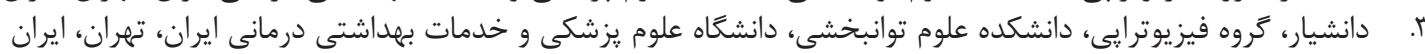

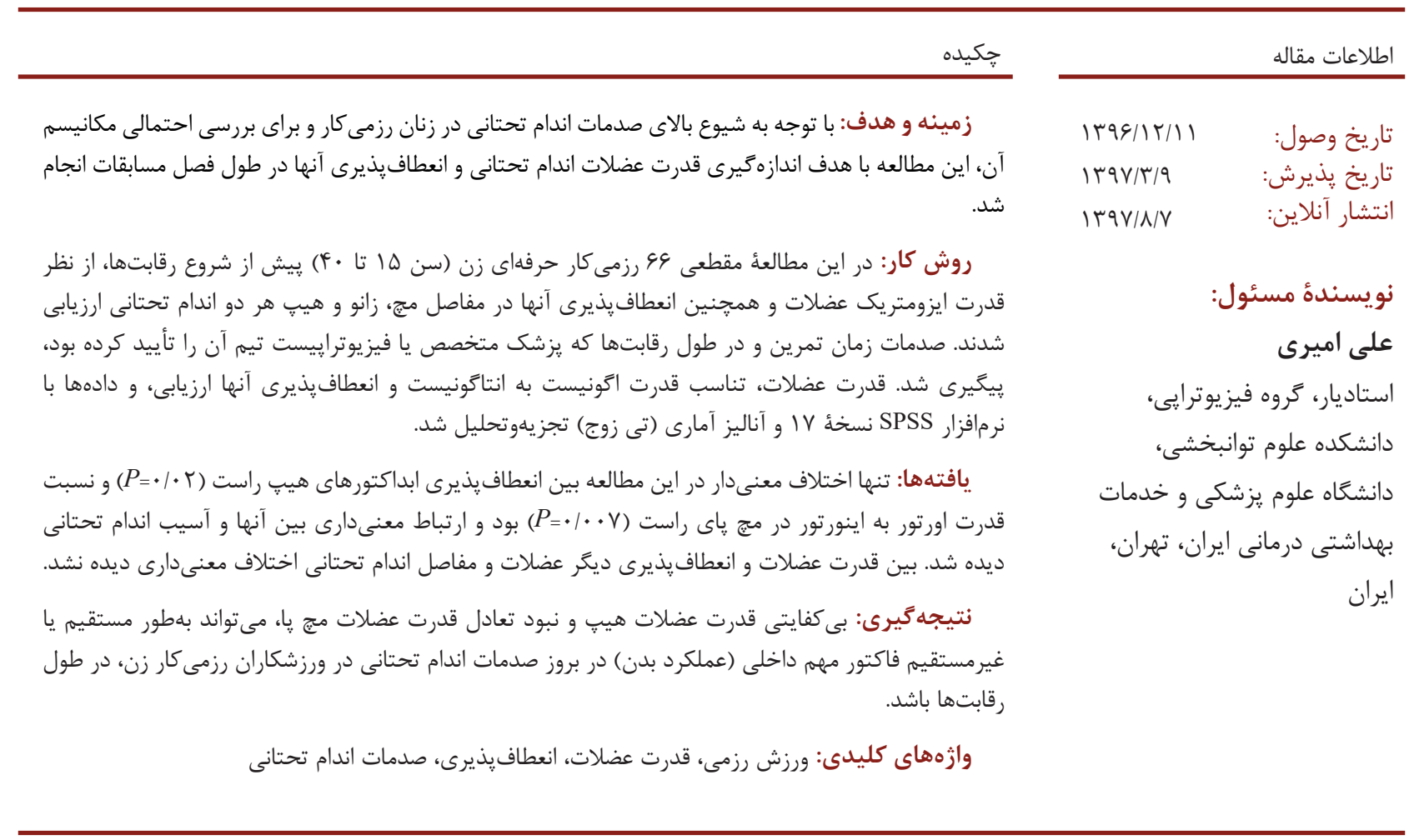

